This is the peer reviewed version of the following article: Faber, M., Wollny, T., Schlegel, M., Wanka, K. M., Thiel, J., Frank, C., Rimek, D., Ulrich, R. G. and Stark, K. (2013), Puumala Virus Outbreak in Western Thuringia, Germany, 2010: Epidemiology and Strain Identification. Zoonoses and Public Health, 60: 549-554. doi: 10.1111/zph.12037, which has been published in final form at http://onlinelibrary. wiley.com/doi/10.1111/zph.12037/abstract. This article may be used for non-commercial purposes in accordance with Wiley Terms and Conditions for Self-Archiving.

\title{
Zoonoses and Public Health (Short Communication) Puumala virus outbreak in western Thuringia, Germany, 2010: Epidemiology and strain identification
}

Mirko Faber $^{1^{*}}$, Theres Wollny ${ }^{2,3}$, Mathias Schlegel ${ }^{2}$, Konrad M. Wanka $^{2}$, Jörg Thiel ${ }^{4}$, Christina Frank ${ }^{1}$, Dagmar Rimek ${ }^{5}$, Rainer G. Ulrich ${ }^{2}$, Klaus Stark ${ }^{1}$

${ }^{1}$ Robert Koch Institute, Department for Infectious Disease Epidemiology, Berlin, Germany

${ }^{2}$ Friedrich-Loeffler-Institut, Institute for Novel and Emerging Infectious Diseases, Greifswald - Insel Riems, Germany

${ }^{3}$ Hochschule Lausitz, Bio-, Chemie- und Verfahrenstechnik, Senftenberg, Germany

${ }^{4}$ THÜRINGENFORST - Anstalt öffentlichen Rechts, Service- und Kompetenzzentrum, Gotha, Germany

${ }^{5}$ Thuringian State Authority for Food-Safety and Consumer Protection (TLLV), Bad Langensalza, Germany

\section{Summary}

In 2010, the highest annual number of human Puumala virus (PUUV) infections was reported in Germany since hantavirus surveillance started in 2001. The increase in annual case numbers was especially marked in western Thuringia. We combined results of case-based hantavirus surveillance in humans and serological and molecular investigations in the rodent reservoir in order to describe the epidemiological situation and to identify the putative outbreak strain.

A five-fold increase in notified hantavirus cases compared to the previous annual maximum was observed in western Thuringia in 2010. Disease incidence varied tremendously within a small geographical area with case patients' places of residence clustering around beech dominated broad leaf forest patches. Investigations in the rodent reservoir revealed a novel Puumala virus (PUUV) subtype, which is clearly distinct from strains collected in other PUUV endemic regions of Germany. It can be assumed that in regions in western Thuringia where hantavirus cases occurred in 2010 or previous outbreak years, PUUV has been present in the environment for a long time. Further studies are needed to elucidate the population dynamics and hantavirus prevalence of the rodent reservoir and driving ecological factors.

Key words: Hantavirus - Puumala virus - bank vole (Myodes glareolus) - Outbreak - Germany

\section{Impact}

- The increase in numbers of human cases in western Thuringia in 2010 was most likely caused by a proliferation of the population of infected vole rather than a recent spread of the hantavirus from other regions.

- Areas with only few notified cases in one year may still see larger outbreaks of nephropathia epidemica in future years with mast driven bank vole population increases.

- Geographical analyses of case data early in outbreak seasons might help to identify areas of higher risk and to better target public health interventions. 


\section{Introduction}

Puumala virus (PUUV) causes the majority of human hantavirus infections in Germany and was found to be the causative agent of regional outbreaks of nephropathia epidemica (NE) in the south and west of the country. The relevant reservoir animal is the bank vole (Myodes glareolus). Previous outbreaks occurred in 2004, 2005, and 2007 with annual case numbers of 242,447 , and 1688 , respectively. The affected areas were predominantly rural and long known to be endemic for PUUV (Ulrich et al., 2004, Essbauer et al., 2006, Abu Sin et al., 2007, Hofmann et al., 2008, Winter et al., 2009).

In the north and east of Germany, sporadic human infections with a genetic lineage of Dobrava-Belgrade virus (DOBV-Aa) associated with Apodemus agrarius have been identified (Klempa et al., 2004, Schlegel et al., 2009). Tula virus (TULV), a third hantavirus, associated with Microtus arvalis and M. agrestis, in Germany seems to cause human infections and clinical symptoms only very rarely (Klempa et al., 2003, Schmidt-Chanasit et al., 2010, Mertens et al., 2011a).

In 2010, the highest number of clinical hantavirus infections with laboratory confirmation ( $n=2016$ corresponding to an incidence of $2.5 / 100,000$ population) was reported since hantavirus surveillance started in Germany in 2001 (RKI, 2011). Remarkably, in some of the high incidence areas of 2010, none or only a few cases had been observed in previous outbreak years. The objective of this study was to describe the epidemiological situation in one of these areas (western Thuringia) and to identify the outbreak virus strain.

\section{Materials and Methods}

We analyzed national hantavirus surveillance data and additional information collected by local health departments in Thuringia. Data were collected during routine case investigation through non-standardized telephone interviews and included cases patients' places of residence (village level) for spatial analyses. Rodents were collected in October 2010 at two different sites in the county of Wartburgkreis (southwestern Thuringia; see Figure 1) using snap traps. The two sampling points represented areas where NE cases did and did not occur earlier in 2010. The necropsy of the rodents was performed as previously described (Ulrich et al., 2011). The morphological species determination was confirmed by cytochrome $b$ specific PCR (Schlegel et al., 2012). The initial serological screening by IgG ELISA using a yeast-expressed $\mathrm{N}$ protein of PUUV strain Bavaria followed a recently published protocol (Mertens et al., 2011b). RNA extraction from lung tissue, S-segment specific RT-PCR, DNA sequence determination and phylogenetic analysis was done as described previously (Essbauer et al., 2006, Mertens et al., 2011b). PUUV sequences obtained from bank voles were compared to published sequences obtained from rodents or patients using a dataset from a recent publication (Ettinger et al., 2012).

\section{Results}

\section{Epidemiology of NE cases}

In 2010, a total of 63 cases of symptomatic hantavirus infection with laboratory confirmation (presence of hantavirus specific $\operatorname{lgM}$, confirmed by $\operatorname{lgG}$ ) were notified in the state of Thuringia (incidence 2.82 per 100,000 population), compared to $n=14,0,8,7,0$ cases per year in 2005 through 2009, respectively (incidence $0.6,0.0,0.35,0.31,0.0$ per 100,000). The 
majority of 2010 case patients ( $n=50 ; 79.4 \%$ ) had a disease onset during May through August.

The outbreak area lies in the Rhön foot hills, where broad agriculturally used valley floors are interspersed with wooded hills and many small villages and towns. A probable place of infection outside the patients' county of residence was reported only for one of the cases.

Most infections ( $n=55 ; 87 \%$ ) were notified by five neighboring counties in the western part of the state corresponding to 10 cases per 100,000 population. Places of residence (town/village level) of cases were predominantly rural and clustered near beech dominated broadleaf forest patches (Figure 1).

The proportion of hospitalized patients ( $82.5 \%$ ) was higher than in other parts of Germany in 2010 (67.6\%, p=0.01) but comparable to 2005 and 2007 in Thuringia ( $78.6 \%$ and $75.0 \%$, respectively). No significant difference was seen regarding mean age $[ \pm S D]$ and sex distribution of case patients in Thuringia ( $42.8[ \pm 16.4]$ years and $69.8 \%$ male) compared to case patients from other parts of Germany ( $43.0[ \pm 14.5]$ years and $71.4 \%$ male), $p>0.75$.

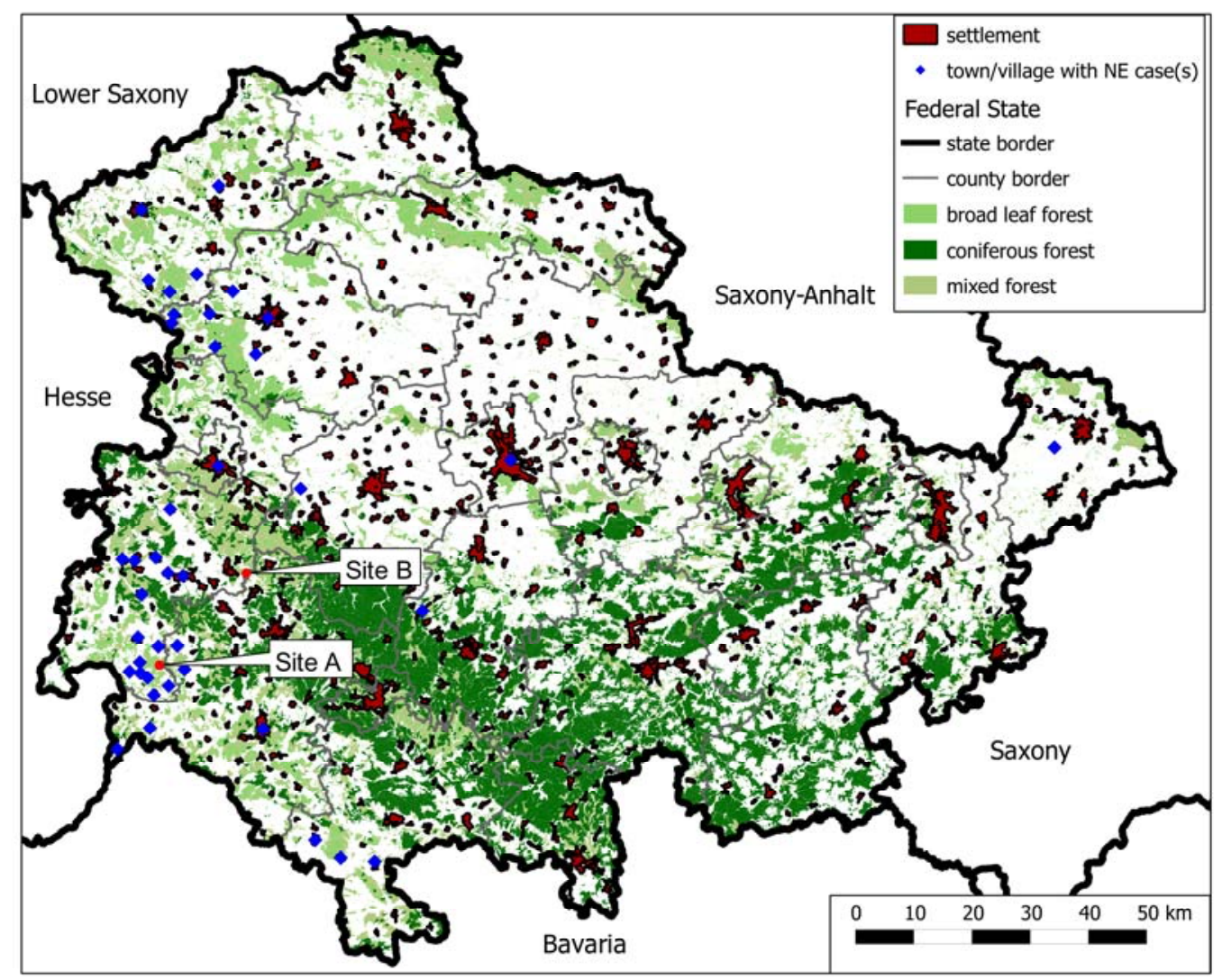

Figure 1: Map of the state of Thuringia showing places of residence (village level, blue diamonds) of $n=57$ symptomatic hantavirus case patients notified in 2010 and the two rodent trapping sites A and B (red dots).

\section{Serological and molecular investigations of the rodent reservoir}

At site A (Figure 1) 67 rodents were collected in 200 trapping nights. Species determination showed 58 to be bank voles (Myodes glareolus), the main PUUV reservoir. In 22 of 56 (39.3 \%) bank voles available for further investigation, PUUV-specific antibodies were detected. Trapping at site B yielded 51 bank voles of which all were PUUV seronegative. Seventeen out of the $22(77.3 \%)$ serologically PUUV positive bank voles from site A were also RT-PCR positive. The obtained RT-PCR amplification products of the S-segment region of the viral genome demonstrated the expected size of around 760 nucleotides. 
The obtained nucleotide sequences from Thuringia demonstrated an intra-cluster divergence of $1.2 \%(0.6 \%)$ in the nucleotide (amino acid) sequence. Interestingly, three PUUV sequence types were found in Thuringia (Figure 2) with type II found in 15 bank voles whereas types I and III were found in only one animal each. Divergence values of $14.7 \%$ (4.2 $\%), 14.5 \%$ (3.6 \%) and 16.5\% (2.4\%) were observed when comparing the novel sequences from Thuringia to published sequences originating from neighboring endemic areas of Hesse, Lower Franconia in Bavaria and Lower Saxony, respectively.

In the phylogenetic analysis, PUUV strains from bank voles obtained in Western Thuringia represent a novel lineage which is clearly separated from PUUV strains obtained from other (including neighboring) geographical regions in Germany and other European countries (Figure 2). 


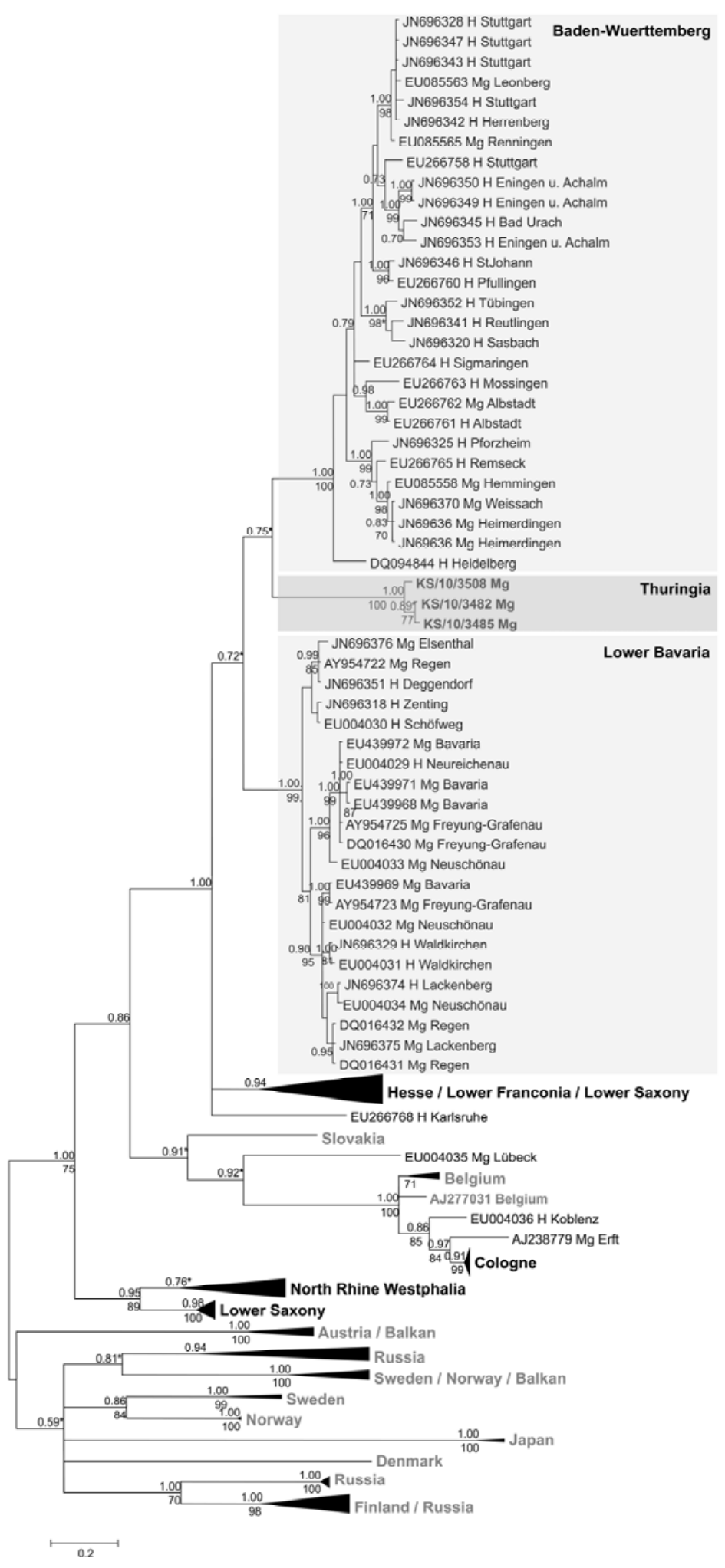

Figure 2: Bayesian-tree based on 504 bp long nucleotide sequences of the S-segment of $n=95$ PUUV sequences from bank voles $(\mathrm{Mg})$ and human NE patients $(\mathrm{H})$ in different hantavirus endemic areas of Germany. Numbers indicate posterior probabilities and bootstrap values based on four chains and two runs with 2000000 generations for Bayesian analysis and 10000 pseudoreplicates for corresponding NeighborJoining (NJ) analysis. For this analysis the dataset from a recent investigation of the PUUV outbreak in Germany was used (Ettinger et al., 2012) and modified by addition of the three sequences from Thuringia. Asterisks indicate differences in the topology between Bayesian- and NJ-tree at this node. 


\section{Discussion}

In 2010, record numbers of notified cases were observed in several parts of Germany. Resembling the outbreak years 2005 and 2007, a high population density of the reservoir animal following a strong beech mast in the preceding year is thought to be a key factor contributing to this circumstance (Schwarz et al., 2009). The reasons for the particularly strong increase in case numbers in western Thuringia compared to previous outbreak years are not clear but could be related to regional differences in the intensity of mast events driving bank vole population size or an increased prevalence of the virus in the rodent reservoir. While an increase in case numbers could also be caused by a raised awareness of the population or practitioners, the steady proportion of hospitalized cases observed during the last years indicates no substantial change in the overall sensitivity of the surveillance system.

While an overall increase in case numbers was observed for several counties in western Thuringia, the actual incidence or risk of infection seemed highly variable within this area: Cases patients' places of residence clustered around broadleaf forest patches suggesting that living in close proximity to forested areas is a risk factor and exposures in and - more likely - around the place of residence play a major role. These findings are consistent with results of case control studies, that have shown an association between disease and living $<100 \mathrm{~m}$ from a forest as well as peridomestic activities such as firewood handling or cleaning utility sheds (Abu Sin et al., 2007, Vapalahti et al., 2010, Winter et al., 2009). Case patients' places of residence clustering around some beech dominated forested areas but not others point to a very focal presence of the virus within vole populations (Linard et al., 2007), which is also reflected in the highly divergent PUUV seropositivity proportions ( $39.3 \%$ vs. $0 \%$ ) of bank voles trapped at two different sites. This apparent small-scale geographical variability of exposure risk underlines the usefulness of geographical analyses of case data early in outbreak seasons for targeting public health recommendations or interventions.

The phylogenetic analysis confirmed previous findings of a high genetic diversity of PUUV strains and the presence of several regions with distinct PUUV subtypes in Germany (Ettinger et al., 2012, Hofmann et al., 2008, Mertens et al., 2011b, Ulrich et al., 2008). Strains obtained from patients and rodents clustered in the respective endemic areas indicating that identification of outbreak strains using rodents is a feasible alternative to obtaining this information from patients, where the time window for nucleic acid detection is small (Schilling et al., 2007). The S-segment nucleotide sequence variability of the PUUV strain detected at site $A$ in Thuringia was found to be $1.2 \%$. Similar nucleotide sequence variabilities of up to $1.2 \%$ were found in the S-segment of PUUV strains detected in bank voles from the city of Cologne and at a single site in the district Göttingen of Lower Saxony (Essbauer et al., 2007, Mertens et al., 2011b). The deep branching of the Thuringian clade may suggest a sustained presence of the virus in the region over a long period of time and an evolution of the respective strain(s) separate from other (including neighboring) areas where PUUV is endemic. The increase in human case numbers in Thuringia in 2010 was thus most likely caused by a proliferation of the population of infected voles rather than a recent spread of the virus from other areas.

As was apparent in Thuringia in 2010, areas with only few notified cases in one year may still see larger outbreaks of NE in future years with mast driven bank vole population increases. 
We therefore recommend to monitor the situation (at least locally) and to inform the public about the situation and preventive measures as soon as case numbers rise in spring. Given the focality of the endemicity, a geographically targeted approach (through postings, leaflets or local press) may be most efficient. Analysis of case data in geographical detail smaller than the county level is helpful to identify locally increased risks of infection and to better target public health recommendations. Regrettably, current data protection regulations preclude routine analyses with increased spatial resolution on the regional or national level.

\section{Acknowledgements}

The authors would like to thank the staff of local health authorities and partners in the networks "Rodent-borne pathogens" and "Arbeitskreis Mäuse im Forst" as well as additional collaborators for their support. The authors kindly acknowledge the technical assistance of Udo Bleske, Ulrike M. Rosenfeld, Gina Lucht, Christian Korthase, Ute Wessels and Franziska Thomas. The work in the laboratory of RGU was supported by the Robert Koch-Institute (Fo_1362/1-924, FKZ 1362/1-980) and the Federal Ministry of Food, Agriculture and Consumer Protection (FKZ 07HSO27).

\section{References}

Abu Sin, M., K. Stark, U. van Treeck, H. Dieckmann, H. Uphoff, W. Hautmann, B. Bornhofen, E. Jensen, G. Pfaff and J. Koch, 2007: Risk factors for hantavirus infection in Germany, 2005. Emerging infectious diseases, 13, 1364-1366.

Essbauer, S., J. Schmidt, F. J. Conraths, R. Friedrich, J. Koch, W. Hautmann, M. Pfeffer, R. Wolfel, J. Finke, G. Dobler and R. Ulrich, 2006: A new Puumala hantavirus subtype in rodents associated with an outbreak of Nephropathia epidemica in South-East Germany in 2004. Epidemiology and infection, 134, 1333-1344.

Essbauer, S. S., J. Schmidt-Chanasit, E. L. Madeja, W. Wegener, R. Friedrich, R. Petraityte, K. Sasnauskas, J. Jacob, J. Koch, G. Dobler, F. J. Conraths, M. Pfeffer, C. Pitra and R. G. Ulrich, 2007: Nephropathia epidemica in metropolitan area, Germany. Emerging infectious diseases, 13, 1271-1273.

Ettinger, J., J. Hofmann, M. Enders, F. Tewald, R. M. Oehme, U. M. Rosenfeld, H. S. Ali, M. Schlegel, S. Essbauer, A. Osterberg, J. Jacob, D. Reil, B. Klempa, R. G. Ulrich and D. H. Kruger, 2012: Multiple synchronous outbreaks of puumala virus, Germany, 2010. Emerging infectious diseases, 18, 1461-1464.

Hofmann, J., H. Meisel, B. Klempa, S. M. Vesenbeckh, R. Beck, D. Michel, J. Schmidt-Chanasit, R. G. Ulrich, S. Grund, G. Enders and D. H. Kruger, 2008: Hantavirus outbreak, Germany, 2007. Emerging infectious diseases, 14, 850-852.

Klempa, B., H. Meisel, S. Rath, J. Bartel, R. Ulrich and D. H. Kruger, 2003: Occurrence of renal and pulmonary syndrome in a region of northeast Germany where Tula hantavirus circulates. Journal of clinical microbiology, 41, 4894-4897.

Klempa, B., M. Schutt, B. Auste, M. Labuda, R. Ulrich, H. Meisel and D. H. Kruger, 2004: First molecular identification of human Dobrava virus infection in central Europe. Journal of clinical microbiology, 42, 1322-1325. 
Linard, C., K. Tersago, H. Leirs and E. F. Lambin, 2007: Environmental conditions and Puumala virus transmission in Belgium. International journal of health geographics, 6, 55.

Mertens, M., J. Hofmann, R. Petraityte-Burneikiene, M. Ziller, K. Sasnauskas, R. Friedrich, O. Niederstrasser, D. H. Kruger, M. H. Groschup, E. Petri, S. Werdermann and R. G. Ulrich, 2011a: Seroprevalence study in forestry workers of a non-endemic region in eastern Germany reveals infections by Tula and Dobrava-Belgrade hantaviruses. Medical microbiology and immunology, 200, 263-268.

Mertens, M., E. Kindler, P. Emmerich, J. Esser, C. Wagner-Wiening, R. Wolfel, R. PetraityteBurneikiene, J. Schmidt-Chanasit, A. Zvirbliene, M. H. Groschup, G. Dobler, M. Pfeffer, G. Heckel, R. G. Ulrich and S. S. Essbauer, 2011b: Phylogenetic analysis of Puumala virus subtype Bavaria, characterization and diagnostic use of its recombinant nucleocapsid protein. Virus genes, 43, 177-191.

RKI, 2011: Infektionsepidemiologisches Jahrbuch meldepflichtiger Krankheiten für 2010 (Yearbook of Infectious Disease Epidemiology 2010). Robert Koch Institute, Berlin, Germany.

Schilling, S., P. Emmerich, B. Klempa, B. Auste, E. Schnaith, H. Schmitz, D. H. Kruger, S. Gunther and H. Meisel, 2007: Hantavirus disease outbreak in Germany: limitations of routine serological diagnostics and clustering of virus sequences of human and rodent origin. Journal of clinical microbiology, 45, 3008-3014.

Schlegel, M., H. S. Ali, N. Stieger, M. H. Groschup, R. Wolf and R. G. Ulrich, 2012: Molecular identification of small mammal species using novel cytochrome $B$ gene-derived degenerated primers. Biochemical genetics, 50, 440-447.

Schlegel, M., B. Klempa, B. Auste, M. Bemmann, J. Schmidt-Chanasit, T. Buchner, M. H. Groschup, M. Meier, A. Balkema-Buschmann, H. Zoller, D. H. Kruger and R. G. Ulrich, 2009: Dobrava-Belgrade virus spillover infections, Germany. Emerging infectious diseases, 15, 2017-2020.

Schmidt-Chanasit, J., S. Essbauer, R. Petraityte, K. Yoshimatsu, K. Tackmann, F. J. Conraths, K. Sasnauskas, J. Arikawa, A. Thomas, M. Pfeffer, J. J. Scharninghausen, W.

Splettstoesser, M. Wenk, G. Heckel and R. G. Ulrich, 2010: Extensive host sharing of central European Tula virus. Journal of virology, 84, 459-474.

Schwarz, A. C., U. Ranft, I. Piechotowski, J. E. Childs and S. O. Brockmann, 2009: Risk factors for human infection with Puumala virus, southwestern Germany. Emerging infectious diseases, 15, 1032-1039.

Ulrich, R., H. Meisel, M. Schutt, J. Schmidt, A. Kunz, B. Klempa, M. Niedrig, G. Pauli, D. H. Kruger and J. Koch, 2004: [Prevalence of hantavirus infections in Germany]. Bundesgesundheitsblatt, Gesundheitsforschung, Gesundheitsschutz, 47, 661-670.

Ulrich, R. G., J. Schmidt-Chanasit, M. Schlegel, J. Jacob, H. J. Pelz, M. Mertens, M. Wenk, T. Buchner, D. Masur, K. Sevke, M. H. Groschup, F. W. Gerstengarbe, M. Pfeffer, R. Oehme, W. Wegener, M. Bemmann, L. Ohlmeyer, R. Wolf, H. Zoller, J. Koch, S. Brockmann, G. Heckel and S. S. Essbauer, 2008: Network "Rodent-borne pathogens" 
in Germany: longitudinal studies on the geographical distribution and prevalence of hantavirus infections. Parasitology research, 103 Suppl 1, S121-129.

Ulrich, R. G., S. Schmidt, U. M. Rosenfeld, M. H. Groschup and M. Schlegel, 2011: HantavirusDiagnostik in Reservoirwirten. LabLoeffler, 4, 13-17.

Vapalahti, K., A. M. Virtala, A. Vaheri and O. Vapalahti, 2010: Case-control study on Puumala virus infection: smoking is a risk factor. Epidemiology and infection, 138, 576-584.

Winter, C. H., S. O. Brockmann, I. Piechotowski, K. Alpers, M. an der Heiden, J. Koch, K. Stark and G. Pfaff, 2009: Survey and case-control study during epidemics of Puumala virus infection. Epidemiology and infection, 137, 1479-1485. 